\title{
A study on initial and continuing losses for design flood estimation in New South Wales
}

\author{
M. El-Kafagee ${ }^{a}$, A. Rahman ${ }^{\text {a }}$ \\ ${ }^{\text {a }}$ School of Engineering, University of Western Sydney, Australia \\ Email: mohammed.el-kafagee@hotmail.com
}

\begin{abstract}
Flood estimation is often required in the design and safety assessment of water infrastructure. Rainfall runoff model is often used in design flood estimation, which needs various inputs on rainfall and catchment characteristics such as rainfall duration, rainfall intensity, rainfall temporal patterns and losses. Loss is defined as the amount of precipitation in a rainfall event that does not appear as direct surface runoff at the stream gauge. The initial loss-continuing loss is the most commonly adopted conceptual loss model in Australia. Currently there is inadequate information on design loss values in Australia which is a major weakness in Australian flood hydrology. The currently recommended design losses in Australian Rainfall and Runoff (ARR) are not compatible with the design rainfall information and are likely to result in significant bias in flood estimation. This can result in either under or over-design of water infrastructure; both of these have important economic significance. Also, the currently recommended ARR design loss values ignore its probabilistic nature.
\end{abstract}

The objective of this paper is to derive improved initial and continuing loss values using data from selected catchments in New South Wales (NSW). This intends to derive mean and median loss values as well as stochastic losses which can be applied with both the Design Event Approach and Joint Probability Approach/Monte Carlo simulation technique to design flood estimation. The method used to estimate continuing loss involves the use of a water balance equation involving a rainfall and runoff event.

A total of 253 rainfall runoff events are selected from five NSW catchments. From the analyses, the median initial loss has been found to be $17 \mathrm{~mm}$ which is closer to the lower limit of the ARR recommended value of $10-35 \mathrm{~mm}$. The median continuing loss value has been found to be $0.94 \mathrm{~mm} / \mathrm{h}$ which is $62 \%$ lower than the ARR recommended value of $2.5 \mathrm{~mm} / \mathrm{h}$. The resulting design floods from the observed loss values are likely to be higher than those obtained from the ARR recommended loss values.

It has been found that the observed initial loss and continuing loss values show a wide variability from storm to storm and catchment to catchment. It is thus more logical to adopt stochastic losses in design flood estimation rather than a fixed value of loss. It has been found that two-parameter Gamma distribution can be used to describe the observed initial loss and continuing loss distributions. The stochastic losses described by the Gamma distribution can be used in design flood estimation by adopting Joint Probability Approach/Monte Carlo simulation technique. The Gamma distribution to be used for this purpose is specified by a mean value of $22 \mathrm{~mm}$ and standard deviation of $19 \mathrm{~mm}$ for initial loss and a mean value of $1.20 \mathrm{~mm} / \mathrm{h}$ and standard deviation of $1.04 \mathrm{~mm} / \mathrm{h}$ for continuing loss.

Keywords: Initial Loss (IL), Continuing Loss (CL), Joint Probability Approach, Monte Carlo simulation technique, Design Floods, Australian Rainfall and Runoff 


\section{INTRODUCTION}

Flooding is one of the worst natural disasters causing millions of dollars of damage every year. In 2010-11 year alone, flood damage bill in Australia has exceeded \$20 billion. Estimation of design floods is an important task in hydrology, which is needed to size water infrastructure such as bridge, culverts and flood embankment, and for various other planning and regulatory purposes such as flood risk assessment, flood insurance studies and flood plain mapping.

Design flood estimation methods can be classified into two major categories: streamflow based methods and rainfall based methods. Rainfall based methods are widely adopted in practice as rainfall data is more readily available than flood data and physical catchment characteristics can easily be incorporated with these types of models . Rainfall based flood estimation methods require a number of input and parameters to transform a design rainfall event into a design flood event. Design loss is one of these input variables. Loss is defined as the amount of rainfall that does not appear as direct surface runoff in the river. Loss includes the precipitation intercepted by vegetation (interception loss), infiltration into the soil, retention on the surface (depression storage), evaporation and loss through the streambed. The amount of loss is dependent on a number of factors such as catchment topography, soil, vegetation, and the antecedent soil moisture.

In design flood estimation, simplified lumped conceptual loss models are commonly used for their simplicity and ability to approximate catchment runoff behavior. The lumped conceptual loss model named as the Initial Loss-Continuing Loss Model is commonly used in Australia (I. E. Aust., 1987). The Initial Loss (IL) is known to be the amount of rainfall that occurs before the start of surface runoff, while the Continuing Loss (CL) is assumed to be the average loss rate throughout the remainder of the rainfall event. The above definition may not completely represent the spatial and temporal distribution of the actual loss in a catchment; however, it is widely used in flood estimation in Australia as this can give quite acceptable design flood estimation. The Australian Rainfall and Runoff (ARR) (I. E. Australia, 1987) has recommended design IL and CL values for different regions of Australia (I. E. Aust., 2001).

Many studies such as Waugh (1991), Walsh et al. (1991), Hill and Mein (1996), Rahman et al. (2002a) and Ilahee et al. (2001) have indicated the limitations of the currently recommended design loss values in ARR. The objective of this paper is to derive IL and CL values for selected catchments in NSW. This includes mean and median loss values as well as stochastic losses so that these can be used with both the Design Event Approach and Joint Probability Approach/Monte Carlo Simulation technique (Rahman et al., 200b) to design flood estimation.

\section{STUDY CATCHMENTS AND DATA}

For this study, five New South Wales catchments are selected as shown in Figure 1 and listed in Table 1. These catchments are rural and do not have any major regulation. The areas of these catchments range 62 $\mathrm{km}^{2}$ to $220 \mathrm{~km}^{2}$. To estimate IL and CL values, two types of data are required: pluviograph and streamflow data. The selected data for this study are summarised in Table 1. The concurrent record lengths of the selected pluviograph and streamflow data range 11 to 35 years. The pluviograph data is obtained from the Australian Bureau of Meteorology and the streamflow data from the Department of Water NSW.

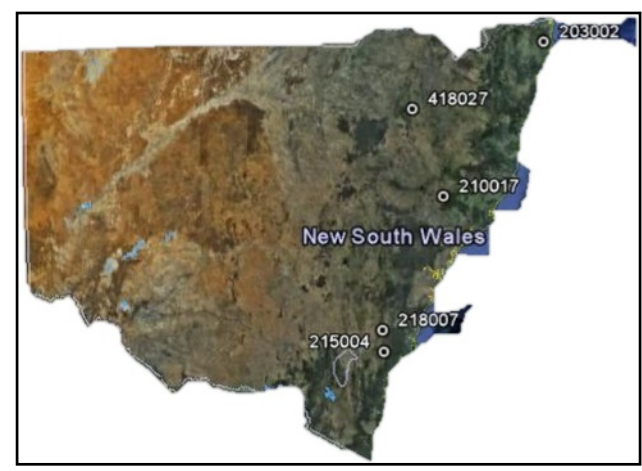

Figure 1. Locations of study catchments in NSW 
Table 1. Selected study catchments and pluviograph stations

\begin{tabular}{|c|c|c|c|c|c|}
\hline $\begin{array}{c}\text { Catchment } \\
\text { ID }\end{array}$ & $\begin{array}{c}\text { River } \\
\text { name }\end{array}$ & $\begin{array}{c}\text { Pluviograph } \\
\text { station }\end{array}$ & $\begin{array}{c}\text { Distance between } \\
\text { stream gauge and } \\
\text { pluviometer }(\mathrm{km})\end{array}$ & $\begin{array}{c}\text { Catchment } \\
\text { area }\left(\mathrm{km}^{2}\right)\end{array}$ & $\begin{array}{c}\text { Record length } \\
\text { (years) }\end{array}$ \\
\hline 218007 & Wadbilliga & 69075 & 7.48 & 122 & 35 \\
\hline 215004 & Corang & 69049 & 5 & 62 & 23 \\
\hline 203002 & Coopers Ck & 58072 & 5 & 220 & 14 \\
\hline 418027 & Horton & 54138 & 7 & 103 & 30 \\
\hline 210017 & Moonan Brook & 61335 & 6.3 & & \\
\hline
\end{tabular}

\section{METHODOLOGY}

\subsection{Selection of rainfall and runoff events}

To estimate losses for a catchment, rainfall and runoff events need to be selected. In this study, a 'complete storm' event is used, which is defined as a period of significant rain preceded and followed by at least six dry hours following the approach of Rahman et al. (2002b). In this method all the storm events exceeding a threshold design rainfall intensity of $0.40 \times{ }^{2} I_{D}$ are taken as the candidate storm events (where ${ }^{2} I_{D}$ is the 2 years average recurrence interval (ARI) and $D$-hour duration rainfall intensity obtained from ARR Volume 2). This threshold allows selection of 3 to 5 candidate rainfall events per year on average from a pluviograph station. These candidate storm events are then examined further to ensure that the corresponding runoff events are consistent i.e. these are not affected by subsequent rainfall events and the total event runoff is smaller than the total event rainfall. In computing losses, a surface runoff threshold value of $0.01 \mathrm{~mm} / \mathrm{h}$ is adopted following the approach of Hill and Mein (1996).

\subsection{Initial loss and continuing loss estimation}

The value of IL is estimated to be the total rainfall that occurs prior to the commencement of surface runoff; whereas CL is the loss that occurs from the beginning of the surface runoff to the end of rainfall event (illustrated in Figure 2). The IL and CL can be expressed using the following water balance equation:

$R=I L+C L * t_{1}+Q F$

Where $\mathrm{R}(\mathrm{mm})$ is the total event rainfall over the catchment, IL is in $m m, \mathrm{CL}$ is in $m m / h, t_{l}$ (h) is the time from the start of surface runoff to the end of rainfall event and QF $(\mathrm{mm})$ is the quick flow generated from the rainfall event.

Quick flow (QF) is calculated by subtracting the baseflow $(\mathrm{BF})$ from total stream flow $\left(\mathrm{SF}_{\mathrm{T}}\right)$. Therefore equation (1) can be expressed as:

$R=I L+C L * t_{1}+\left(S F_{T}-B F\right)$

To estimate CL, equation (1) can be expressed as:

$C L=(R-I L-Q F) / t_{1}$

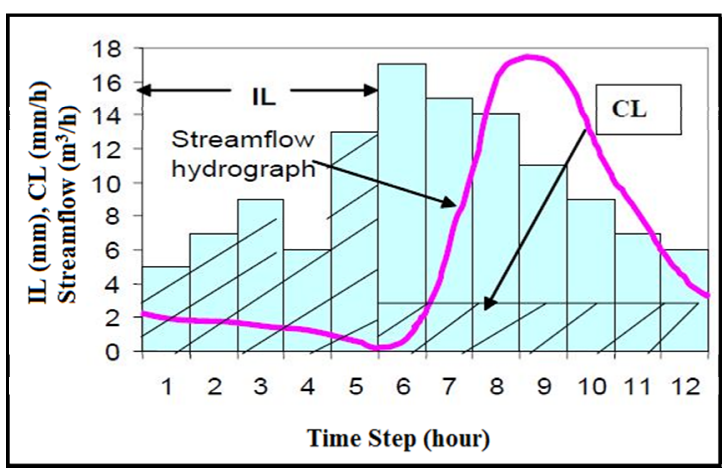

Figure 2. Initial loss $(I L)$ and continuing loss $(C L)$ model for a complete storm

\subsection{Baseflow separation}

For baseflow separation, the method proposed by Boughton (1988) is adopted, which assumes that the rate of increase in the baseflow depends on a fraction of the surface runoff $\alpha$. Therefore, the baseflow at any time step $i\left(B F_{i}\right)$ can be expressed as the baseflow in the previous time step $\left(B F_{i-1}\right)$ plus $\alpha$ times the difference of total streamflow at step $i\left(S F_{i}\right)$ and baseflow $B F_{i-1}$. At the beginning of surface runoff, the baseflow is assumed to be equal to the streamflow i.e. $B F_{i}=S F_{i}$. This can be expressed as: 
$B F_{i}=B F_{i-1}+\alpha\left(S F_{i}-B F_{i-1}\right)$

To apply equation (4), $\alpha$ value needs to be estimated from the observed streamflow events in such a way that the adopted $\alpha$ value provides a reasonable baseflow separation for majority of the selected events for the catchment. It is evident that as $\alpha$ value increases a larger proportion of the total flow is separated (Figure 3 ). A design $\alpha$ value is selected for a catchment by trial and error to achieve an acceptable baseflow separation for the catchment.

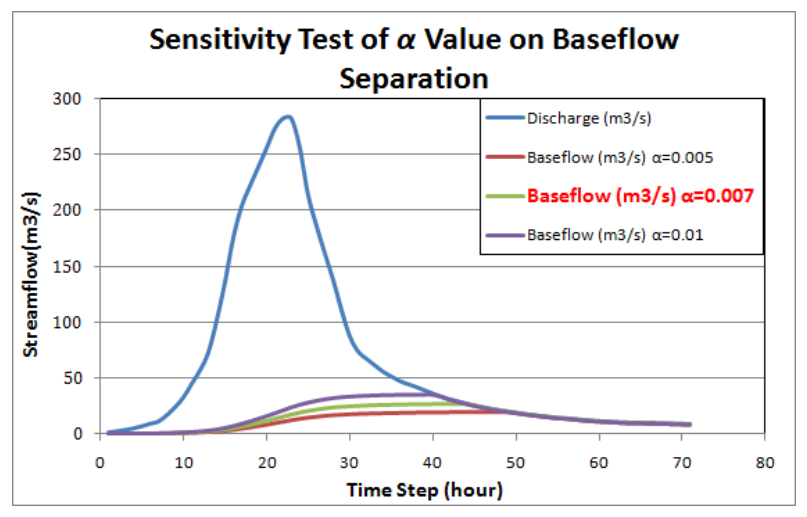

Figure 3. Baseflow separation method

\subsection{Fitting a theoretical distribution to observed loss data}

In the Joint Probability Approach/Monte Carlo simulation technique of design flood estimation (Rahman et al., 2002b), probability distributed losses are adopted. For example, Rahman et al. (2002a) adopted a fourparameter Beta distribution for IL. In this study, one-parameter Exponential and two-parameter Gamma distributions are tested to assess whether they can be used to describe the IL and CL distributions for the study catchments in NSW. To test the statistical hypothesis that the observed IL or CL values follow either an Exponential or Gamma distribution, two different tests are applied: Kolmogorov-Smirnov test and Anderson-Darling (A-D) test at the 5\% level of significance. The Kolmogorov-Smirnov test is based on the maximum difference $\left(D_{\max }\right)$ between the observed cumulative distribution function $F_{n}(x)$ and expected cumulative distribution function $F_{o}(x)$. The Anderson-Darling test gives a heavier weighting to the tails of a distribution where unexpectedly high or low values, called outliers might be present (Kottegoda and Rosso, 1997).

\section{RESULTS}

A total of 253 rainfall and runoff events are selected from the 5 study catchments. It is found that a $\alpha$ value of 0.01 provides a reasonable baseflow separation for the majority of the selected events. The computed CL values are found not to be too sensitive to the selection of $\alpha$ value.

Tables 2 and 3 provide summary statistics of the derived IL and CL values. Considering all the 253 events, the median IL value is found to be $16.89 \mathrm{~mm}$ (range: $0.13 \mathrm{~mm}$ to $111.53 \mathrm{~mm}$ ). The average IL value is 21.84 $\mathrm{mm}$ with a standard deviation of $18.88 \mathrm{~mm}$ and a coefficient of variation of 0.86 . These results highlight that the observed IL values exhibit a high variability across storms and catchments. The median CL value is found to be $0.94 \mathrm{~mm} / \mathrm{h}$ (range: $0.003 \mathrm{~mm} / \mathrm{h}$ to $6.42 \mathrm{~mm} / \mathrm{h}$ ). The average CL value is $1.20 \mathrm{~mm} / \mathrm{h}$ with a standard deviation of $1.20 \mathrm{~mm} / \mathrm{h}$ and a coefficient of variation of 0.87 . These results highlight that the observed CL values show a wide variability across storm events and catchments similar to IL. Given the variability of the observed IL and CL values, it appears to be a difficult task to select a representative value of IL and CL in the application of the Design Event Approach of design flood estimation as recommended by ARR 1987 (I. E. Aust., 1987). Thus, it is more logical to specify stochastic losses, as discussed below, which can be applied with the Monte Carlo simulation technique to design flood estimation. 
The observed median IL value is towards the lower limit of the ARR1987 recommended value of 10-35 $\mathrm{mm}$ for eastern NSW. The observed median CL value is $62 \%$ lower than the ARR1987 recommended value of $2.5 \mathrm{~mm} / \mathrm{h}$.

In specifying the stochastic losses, the empirical distributions of the $I L$ and $C L$ values are examined in Figures 4 and 5 . These figures show that the majority of the observed IL and CL values are smaller than 50 $\mathrm{mm}$ and $1.5 \mathrm{~mm} / \mathrm{h}$, respectively. Based on the Kolmogorov-Smirnov and Anderson-Darling tests, it is found that the Gamma distribution can be used to specify the observed IL and CL distributions at the 0.05 level of significance. That is, the stochastic IL distribution is specified by a Gamma distribution with mean $=22 \mathrm{~mm}$ and standard deviation $=19 \mathrm{~mm}$. The stochastic CL distribution is specified by a Gamma distribution with mean $=1.20 \mathrm{~mm} / \mathrm{h}$ and standard deviation $=1.04 \mathrm{~mm} / \mathrm{h}$. These stochastic losses can be applied with the Monte Carlo simulation technique to design flood estimation for eastern NSW.

Table 2. Summary of results (Initial Loss) $(\mathrm{LL}=$ lower limit and $\mathrm{UL}=$ upper limit)

\begin{tabular}{|c|c|c|c|c|c|c|}
\hline \multirow{2}{*}{ Catchments } & \multirow{2}{*}{ No. of Events } & \multicolumn{7}{|c|}{ Initial Loss } \\
\cline { 3 - 7 } & & LL (mm) & UL (mm) & Mean (mm) & Median (mm) & SD (mm) \\
\hline Coopers Ck & 97 & 0.3 & 55.85 & 15.65 & 12.78 & 12.69 \\
\hline Corang & 41 & 0.13 & 76.11 & 22.2 & 16.5 & 18.49 \\
\hline Horton & 76 & 0.46 & 111.53 & 29.85 & 24.37 & 22.99 \\
\hline Moonan Brook & 10 & 0.27 & 10.04 & 5.23 & 5.64 & 2.91 \\
\hline Wadbilliga & 29 & 0.6 & 60.65 & 26.8 & 27.64 & 17.82 \\
\hline ALL EVENTS & 253 & 0.13 & 111.53 & 21.84 & 16.89 & 18.88 \\
\hline
\end{tabular}

Table 3. Summary of results (Continuing Loss) $(\mathrm{LL}=$ lower limit and UL = upper limit)

\begin{tabular}{|c|c|c|c|c|c|c|}
\hline \multirow{2}{*}{ Catchments } & \multirow{2}{*}{ No. of Events } & \multicolumn{5}{|c|}{ Continuing Loss } \\
\cline { 3 - 7 } & & LL (mm/h) & UL $(\mathbf{m m} / \mathbf{h})$ & $\begin{array}{c}\text { Mean } \\
(\mathbf{m m} / \mathbf{h})\end{array}$ & $\begin{array}{c}\text { Median } \\
(\mathbf{m m} / \mathbf{h})\end{array}$ & SD (mm/h) \\
\hline Coopers Ck & 97 & 0.06 & 4.2 & 1.47 & 1.27 & 0.96 \\
\hline Corang & 41 & 0.03 & 3.11 & 0.76 & 0.53 & 0.72 \\
\hline Horton & 76 & 0.003 & 4.46 & 0.88 & 0.58 & 0.94 \\
\hline Moonan Brook & 10 & 0.23 & 1.99 & 0.95 & 0.90 & 0.57 \\
\hline Wadbilliga & 29 & 0.25 & 6.42 & 1.84 & 1.56 & 1.43 \\
\hline ALL EVENTS & $\mathbf{2 5 3}$ & $\mathbf{0 . 0 0 3}$ & $\mathbf{6 . 4 2}$ & $\mathbf{1 . 2 0}$ & $\mathbf{0 . 9 4}$ & $\mathbf{1 . 0 4}$ \\
\hline
\end{tabular}




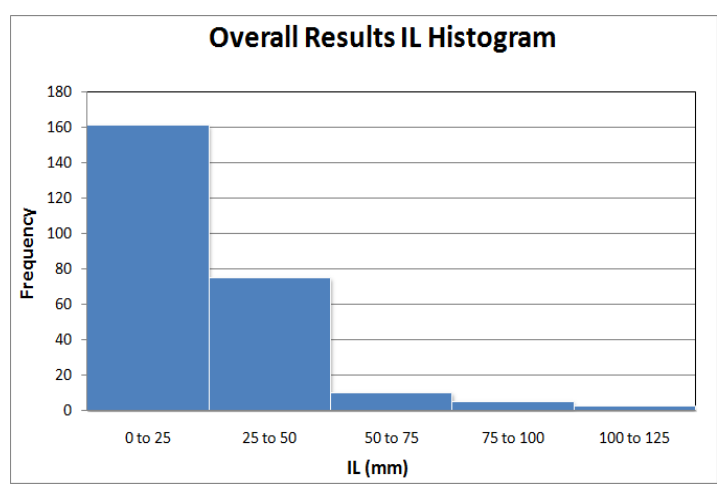

Figure 4. Distribution of observed IL values

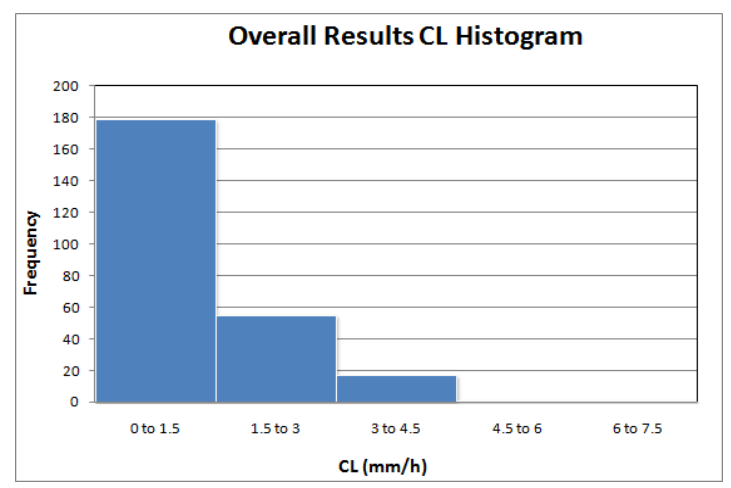

Figure 5. Distribution of observed CL values

\section{CONCLUSIONS}

The study examines initial and continuing loss values for 253 rainfall and runoff events selected from five NSW catchments. The following conclusions can be drawn from this study:

- The newly derived losses for NSW are lower than the ARR1987 recommended values. The median initial loss value is found to be $17 \mathrm{~mm}$ which is closer to the lower limit of the ARR1987 recommended value of 10-35 $\mathrm{mm}$. The median continuing loss value is estimated to be $0.94 \mathrm{~mm} / \mathrm{h}$ which is $62 \%$ lower than the ARR recommended value of $2.5 \mathrm{~mm} / \mathrm{h}$. The design flood estimates based on these new loss values are expected to be higher than those obtained from the ARR1987 recommended values.

- The observed initial loss and continuing loss values show a wide variability from storm to storm and catchment to catchment. It is thus more logical to adopt stochastic losses in design flood estimation rather than fixed values of losses.

- It has been found that two-parameter Gamma distribution can be used to describe the observed initial loss and continuing loss distributions. The stochastic losses described by the Gamma distribution can be used in design flood estimation by adopting Joint Probability Approach/Monte Carlo simulation technique. The Gamma distribution to be used for this purpose is specified by a mean value of $22 \mathrm{~mm}$ and standard deviation of $19 \mathrm{~mm}$ for initial loss, and a mean value of 1.20 $\mathrm{mm} / \mathrm{h}$ and standard deviation of $1.04 \mathrm{~mm} / \mathrm{h}$ for continuing loss.

\section{REFERENCES}

Boughton, W. C. 1988. Partitioning streamflow by computer, The I. E. Aust., Civil Eng. Trans., pp. $285-291$. Hill, P. I. and Mein, R. G. 1996. Incompatibilities between storm temporal patterns and losses for design flood estimation, Hydrology and Water Resources Symposium, Hobart, vol. 2, pp. 445-451.

Ilahee, M., Rahman, A. and Boughton, W. C. 2001. Probability-distributed initial losses for flood estimation in Queensland, Proceedings of the International Congress on Modelling and Simulation.

Institution of Engineers Australia. 1987. Australian rainfall and Runoff: A Guide to Design Flood Estimation, Institution of Engineers, Australia.

Institution of Engineers Australia. 2001. Australian rainfall and Runoff: A Guide to Design Flood Estimation, Institution of Engineers, Australia.

Kottegoda, N.T. and Rosso, R. 1997. Statistics, Probability, and Reliability for Civil and Environmental Engineers, McGraw-Hill, 1997.

Rahman, A., Weinmann, P. E. and Mein, R. G. 2002a. The use of probability-distributed initial losses in design flood estimation, Australian Journal of Water resources, 6, 1, pp. 17-30.

Rahman, A., Weinmann, P.E., Hoang, T.M.T. Laurenson, E.M. 2002b. Monte Carlo Simulation of flood frequency curves from rainfall. Journal of Hydrology, 2002a, 256 (3-4), 196-210.

Walsh, M.A., Pilgrim, D.H. and Cordery, I. 1991. Initial losses for design flood estimation in New South Wales, International Hydrology and Water Resources Symposium, Perth, pp. 283-288.

Waugh, A.S. 1991. Design losses in flood estimation. International Hydrology and Water Resources Symposium, Perth, pp. 629-30. 